Research Article

\title{
Robust Finite-Time Terminal Sliding Mode Control for a Francis Hydroturbine Governing System
}

\author{
Fengjiao Wu, Junling Ding, and Zhengzhong Wang \\ College of Water Resources and Architectural Engineering, Northwest A\&F University, Yangling 712100, China \\ Correspondence should be addressed to Zhengzhong Wang; wangzz0910@163.com
}

Received 4 May 2016; Accepted 27 July 2016

Academic Editor: Enrique Onieva

Copyright ( 2016 Fengjiao Wu et al. This is an open access article distributed under the Creative Commons Attribution License, which permits unrestricted use, distribution, and reproduction in any medium, provided the original work is properly cited.

\begin{abstract}
The robust finite-time control for a Francis hydroturbine governing system is investigated in this paper. Firstly, the mathematical model of a Francis hydroturbine governing system is presented and the nonlinear vibration characteristics are analyzed. Then, on the basis of finite-time control theory and terminal sliding mode scheme, a new robust finite-time terminal sliding mode control method is proposed for nonlinear vibration control of the hydroturbine governing system. Furthermore, the designed controller has good robustness which could resist external random disturbances. Numerical simulations are employed to verify the effectiveness and superiority of the designed finite-time sliding mode control scheme. The approach proposed in this paper is simple and also provides a reference for relevant hydropower systems.
\end{abstract}

\section{Introduction}

In the last two decades, the world's total energy demand has dramatically increased. Renewable energy has got more and more attention [1]. Many countries take the hydropower development in the first place. With the increase in hydropower stations, the hydropower system security and stability face more challenges [2-5]. As we know, hydroturbine governing system (HGS) plays an important role in maintaining the safety, stability, and economical operation for hydropower plant. However, HGS is a nonlinear, timevarying and nonminimum phase systems [6,7]. The internal uncertainty of the dynamics and variability of external environment disturbance increase the difficulty of HGS stability analysis and control.

Scholars have made many important contributions on the stability analysis of HGS [8-11]. Based on the above theoretical results, stability control of HGS has become a hot topic recently. Many control methods have been proposed such as the classical PID control [12], sliding mode control [13], intelligent control [14], and identification control [1517]. However, all of the mentioned control methods are based on the stability theory of Lyapunov stability theorem and asymptotic stability theory. The dynamic quality of the transition process is little considered. From the view of improving control quality and time optimization, finitetime control technique could greatly improve the maximum deviation and the transition time of the system and has better robustness and anti-interference capability $[18,19]$.

Sliding mode control is an essentially nonlinear control strategy with a fast response, good dynamic characteristics, and insensitivity to external changes and many other attractive advantages $[20,21]$. In the conventional sliding mode control process, usually a linear sliding surface is selected. When the system reaches the sliding mode, the tracking error converges to zero, and the asymptotic convergence rate could be regulated by selecting sliding surface parameters. However, in any case, the tracking error will not converge to zero within a finite time $[22,23]$.

That is, both finite-time control in improving the transition process and sliding mode control in inhibiting external disturbances have potential advantages. Researchers have tried to combine these two techniques and proposed finitetime terminal sliding mode (TSM) method. But the conventional TSM is often selected as $s=x_{2}+\beta x_{1}^{q / p}$. The form of this sliding mode often causes the singularity problem around the equilibrium. To address this problem, [24] proposes an improved version of TSM, which is expressed as 
$s=\dot{x}+\beta|x|^{\gamma} \operatorname{sign}(x)$. Then the authors also propose a fast $\operatorname{TSM} s=\dot{x}+\alpha x+\beta|x|^{\gamma} \operatorname{sign}(x)$, which enables faster and higher-precision tracking performance than common TSM. Until now, some finite-time sliding mode control techniques for nonlinear systems have been proposed [25-27]. However, to the best of our knowledge, there is very little literature combining finite-time stability theory with sliding mode control for HGS. Could finite-time control of nonlinear HGS be implemented via sliding mode? If the hypothesis is true, what are the specific mathematical derivation and controller forms? There are no relevant results yet. It is still an open problem. Research in this area should be meaningful and challenging.

In light of the above analysis, there are several advantages which make our study attractive. Firstly, the mathematical model of a Francis HGS is introduced. Then, based on finite-time stability theory and sliding mode scheme, a novel finite-time terminal sliding mode control method is designed for the stability control of HGS. Furthermore, the control method could resist random disturbances, which shows the good robustness. Simulation results indicate the designed finite-time sliding mode control scheme works well compared with the existing method.

The remaining contents of our paper are organized as follows. In Section 2, the nonlinear model of a Francis HGS is introduced. The design of finite-time controller for HGS is presented in Section 3. Numerical simulations are drawn in Section 4 . Section 5 concludes this paper.

\section{Nonlinear Modeling of Hydroturbine Governing System}

Here, a Francis turbine which is widely used in China is selected as the research object. The hydroturbine governing system consists of four parts including the hydroturbine model, generator model, water diversion system model, and hydraulic servo system model.

2.1. Nonlinear Hydroturbine Model. The dynamic characteristics of the hydroturbine could be expressed as

$$
\begin{aligned}
M_{t} & =M_{t}(H, N, a), \\
Q_{t} & =Q_{t}(H, N, a),
\end{aligned}
$$

where $M_{t}, Q_{t}, H, N$, and $a$ represent the turbine's active torque, flow, water head, rotational speed, and guide vane opening, respectively.

Mark the relative deviations of the dynamic performance parameters $M_{t}, Q_{t}, H, N, a$ as $m_{t}, q_{t}, h, n, y$, respectively. The dynamic expression of the turbine in the stable operating point using Taylor series expansion with more than two times higher order items ignored:

$$
\begin{gathered}
\Delta m_{t}=\frac{\partial m_{t}}{\partial h} \Delta h+\frac{\partial m_{t}}{\partial n} \Delta n+\frac{\partial m_{t}}{\partial y} \Delta y, \\
\Delta q_{t}=\frac{\partial q_{t}}{\partial h} \Delta h+\frac{\partial q_{t}}{\partial n} \Delta n+\frac{\partial q_{t}}{\partial y} \Delta y
\end{gathered}
$$

where $\partial m_{t} / \partial h$ is the transfer coefficient of turbine torque on the water head; $\partial m_{t} / \partial n$ is the transfer coefficient of turbine torque on the speed; $\partial m_{t} / \partial n$ is the transfer coefficient of turbine torque on the main servomotor stroke; $\partial m_{t} / \partial n$ is the transfer coefficient of turbine torque on the water head; $\partial q_{t} / \partial h$ is the transfer coefficient of turbine flow on the head; $\partial q_{t} / \partial n$ is the transfer coefficient of turbine flow on the speed; $\partial q_{t} / \partial y$ is the transfer coefficient of turbine flow on the main servomotor stroke.

In order to facilitate the analysis and calculation, let $e_{h}$, $e_{n}, e_{y}, e_{q h}, e_{q n}, e_{q y}$ express $\partial m_{t} / \partial h, \partial m_{t} / \partial n, \partial m_{t} / \partial y, \partial q_{t} / \partial h$, $\partial q_{t} / \partial n, \partial q_{t} / \partial y$, respectively. Equation (2) can be rewritten as follows:

$$
\begin{aligned}
\Delta m_{t} & =e_{h} \Delta h+e_{n} \Delta n+e_{y} \Delta y, \\
\Delta q_{t} & =e_{q h} \Delta h+e_{q n} \Delta n+e_{q y} \Delta y .
\end{aligned}
$$

The Laplace transform of (3) can be described as

$$
\begin{aligned}
m_{t}(s) & =e_{h} h(s)+e_{n} n(s)+e_{y} y(s), \\
q_{t}(s) & =e_{q h} h(s)+e_{q n} n(s)+e_{q y} y(s) .
\end{aligned}
$$

In practice, $e_{n}$ and $e_{q n}$ are no longer considered separately, so (4) could be simplified as

$$
\begin{aligned}
m_{t}(s) & =e_{h} h(s)+e_{y} y(s), \\
q_{t}(s) & =e_{q h} h(s)+e_{q y} y(s) .
\end{aligned}
$$

2.2. Water Diversion System Model. For a simple water diversion system, when the effect of water and the elasticity of the pipe wall on the water hammer are small, it can be considered as rigid water hammer. It is assumed that the water is incompressible liquid and pressure pipeline is rigid; then the relationship between water head and flow of water diversion system can be expressed as

$$
\begin{aligned}
h & =-T_{w} \dot{q}, \\
T_{w} & =\frac{Q_{r}}{g H_{r}} \sum \frac{L_{i}}{F_{i}},
\end{aligned}
$$

where $T_{w}$ is the water inertia time constant; $H_{r}$ represents the rated head; $Q_{r}$ means the rated flow; $L_{i}$ is the length of each section of the water diversion pipeline. $F_{i}$ is the crosssectional area of each water diversion pipeline segment.

The transfer function of (6) is described as

$$
G_{h}(s)=\frac{h(s)}{q(s)}=-T_{w} s .
$$

Considering the turbine module and the water diversion system module together, the transfer function of the turbine and the water diversion system can be got as

$$
G_{t}(s)=\frac{e_{y}-\left(e_{q y} e_{h}-e_{q h} e_{y}\right) T_{w} s}{1+e_{q h} T_{w} s} .
$$


2.3. Generator Model. The second-order nonlinear model of the generator can be described as follows:

$$
\begin{aligned}
& \dot{\delta}=\omega_{0} \omega, \\
& \dot{\omega}=\frac{1}{T_{a b}}\left[m_{t}-m_{e}-D \omega\right],
\end{aligned}
$$

where $\delta$ represents the generator's rotor angle; $\omega$ is the relative deviation of the rotational speed of the generator; $D$ is the damping coefficient of the generator. When analyzing the generator dynamic features, if the impact of generator speed vibration on the torque is included in the generator damping coefficient, so the electromagnetic torque and electromagnetic power are equal; that is, $m_{\varepsilon}=P_{e}$, and the electromagnetic power is

$$
P_{e}=\frac{E_{q}^{\prime} V_{s}}{x_{d \Sigma}^{\prime}} \sin \delta+\frac{V_{s}^{2}}{2} \frac{x_{d \Sigma}^{\prime}-x_{q \Sigma}}{x_{d \Sigma}^{\prime} x_{q \Sigma}} \sin 2 \delta,
$$

where $E_{q}^{\prime}$ is transient electromotive force of $q$ axis and $V_{s}$ is infinite system bus voltage of the power system

$$
\begin{aligned}
& x_{d \Sigma}^{\prime}=x_{d}^{\prime}+x_{T}+\frac{1}{2} x_{L}, \\
& x_{q \Sigma}=x_{q}+x_{T}+\frac{1}{2} x_{L},
\end{aligned}
$$

where $x_{d}^{\prime}$ is transient reactance of $d$ axis, $x_{q}$ is synchronous reactance of $q$ axis, $x_{T}$ is transformer short circuit reactance, and $x_{L}$ is transmission line reactance, respectively.

2.4. Hydraulic Servo System Model. When the turbine generator works at rated conditions with disturbances, the differential equation for the main relay can be expressed as

$$
\frac{d y}{d t}=(u-y) \frac{1}{T_{y}},
$$

where $u$ represents the output of speed governor. In this paper, we assume $u=0$, so (12) can be rewritten as

$$
\frac{d y}{d t}=-\frac{1}{T_{y}} y .
$$

Based on (8) and (13), the output torque of the turbine could be given as

$$
\dot{m}_{t}=\frac{1}{e_{q h} T_{w}}\left[-m_{t}+e_{y} y+\frac{e e_{y} T_{w}}{T_{y}} y\right] .
$$

Combining (9)-(14), the nonlinear dynamic model of the hydroturbine governing system can be described as

$$
\begin{aligned}
\dot{\delta} & =\omega_{0} \omega, \\
\dot{\omega} & =\frac{1}{T_{a b}}\left[m_{t}-D \omega-\frac{E_{q}^{\prime} V_{s}}{x_{d \Sigma}^{\prime}} \sin \delta\right. \\
& \left.-\frac{V_{s}^{2}}{2} \frac{x_{d \Sigma}^{\prime}-x_{q \Sigma}}{x_{d \Sigma}^{\prime} x_{q \Sigma}} \sin 2 \delta\right],
\end{aligned}
$$

$$
\begin{aligned}
& \dot{m}_{t}=\frac{1}{e_{q h} T_{w}}\left[-m_{t}+e_{y} y+\frac{e e_{y} T_{w}}{T_{y}} y\right], \\
& \dot{y}=-\frac{1}{T_{y}} y
\end{aligned}
$$

where $\delta, \omega, m_{t}, y$ are dimensionless variables and $\omega_{0}, T_{a b}$, $D, E_{q}^{\prime}, x_{d \Sigma}^{\prime}, x_{q \Sigma}, T_{w}, T_{y}, V_{s}, e_{q h}, e_{y}, e$ are dimensionless parameters. The parameters are selected as $\omega_{0}=300, T_{a b}=19$, $D=2.0, E_{q}^{\prime}=1.35, x_{d \Sigma}^{\prime}=1.25, x_{q \Sigma}=1.474, T_{w}=0.8$, $T_{y}=0.1, V_{s}=1.0, e_{q h}=0.5, e_{y}=1.0$, and $e=0.7$. In order to facilitate the analysis, $x, y, z, w$ are used to replace $\delta, \omega, m_{t}, y$, respectively. In actual operation, the hydroturbine governing system is often affected by the uncertain load changes. In practice, the exact values of the system uncertainties are difficult to know. However, in most practical examples, the upper bound of the nonlinear systems uncertainties can be estimated, and the states of the nonlinear systems are globally bounded [28]. In this paper, the limitation value is set as 1 . So the random load disturbance is considered: $d_{1}(t)=0.8$ rand $(1), d_{2}(t)=0.1 \mathrm{rand}(1), d_{3}(t)=$ 0.5 rand $(1), d_{4}(t)=0.9$ rand (1). Substituting the parameters into system (15), after some calculation, the mathematical model of hydroturbine governing system under the random load disturbance could be described as

$$
\begin{aligned}
\dot{x}= & 300 y+0.8 \text { rand }(1), \\
\dot{y}= & -\frac{2}{19} y+\frac{1}{19} z-\frac{1}{19}(1.08 \sin x+0.061 \sin 2 x) \\
& +0.1 \text { rand }(1), \\
\dot{z}= & -2.5 z+6.6 w+0.5 \text { rand }(1), \\
\dot{w}= & -10 w+0.9 \text { rand }(1) .
\end{aligned}
$$

The time domain of system (16) is illustrated in Figure 1. It is clear that the hydroturbine governing system is in unstable operation and nonlinear vibration. So it is necessary to design corresponding controller to ensure the safe and stable operation of the hydroturbine governing system.

\section{Designing of Finite-Time Terminal Sliding Mode Controller}

To get the main results, the following lemma of finite-time stability is given firstly.

Lemma 1 (see [29]). If there is a continuous positive definite function $V(t)$ satisfying the following differential inequality

$$
\dot{V}(t) \leq-c V^{\eta}(t), \quad \forall t \geq t_{0}, V\left(t_{0}\right) \geq 0,
$$

where $c>0,0<\eta<1$ are two constants, then, for any given $t_{0}, V(t)$ satisfies the following inequality:

$$
\begin{aligned}
V^{1-\eta}(t) & \leq V^{1-\eta}(t)-c(1-\eta)\left(t-t_{0}\right), \quad t_{0} \leq t \leq t_{1}, \\
V(t) & \equiv 0, \quad \forall t \geq t_{1},
\end{aligned}
$$




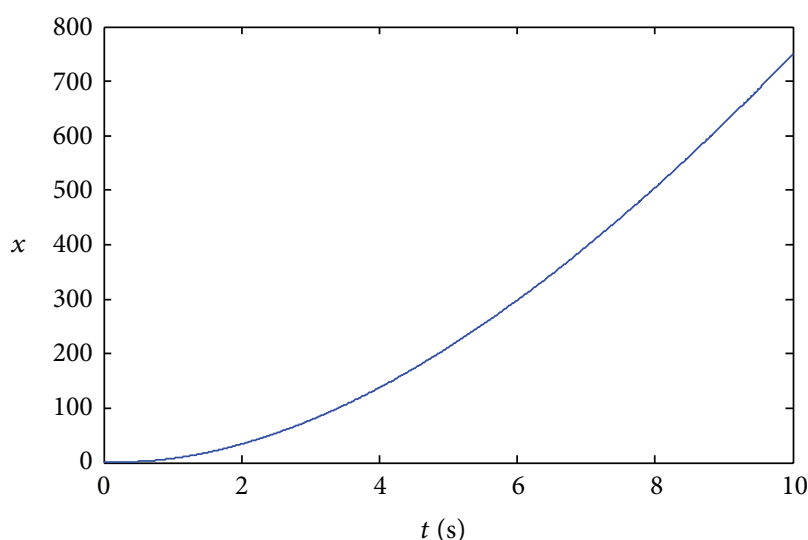

(a) $x-t$

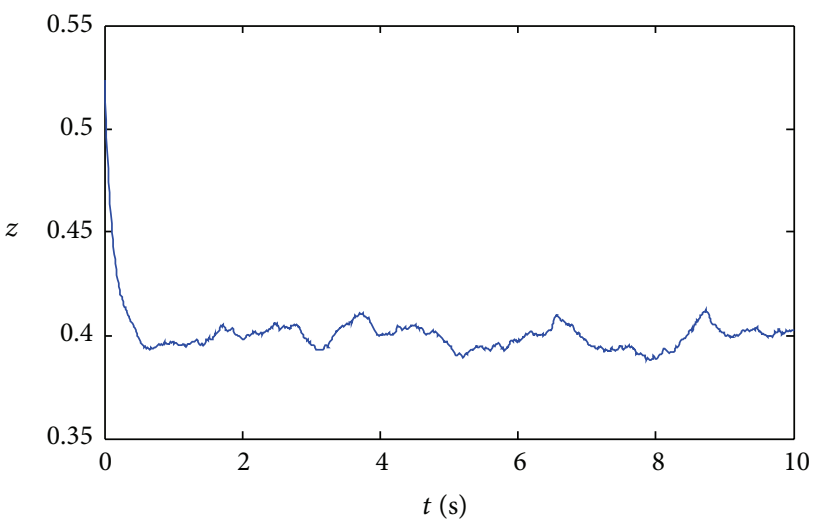

(c) $z-t$

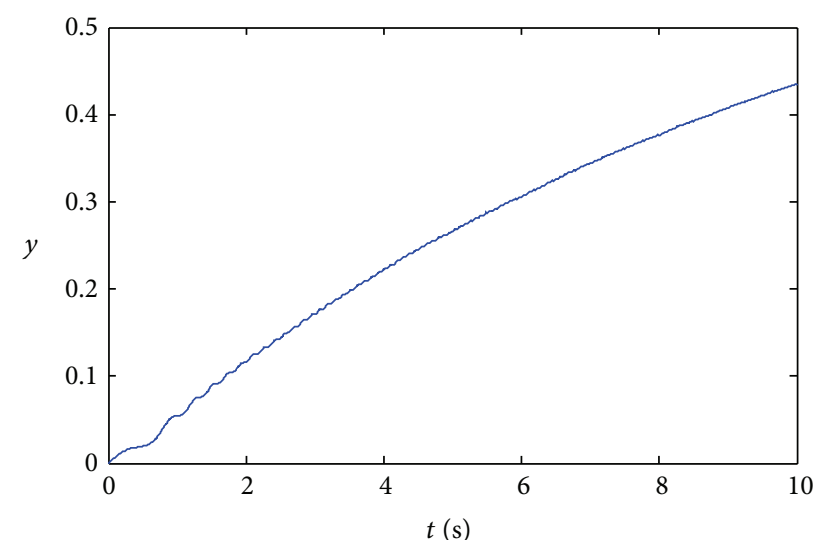

(b) $y-t$

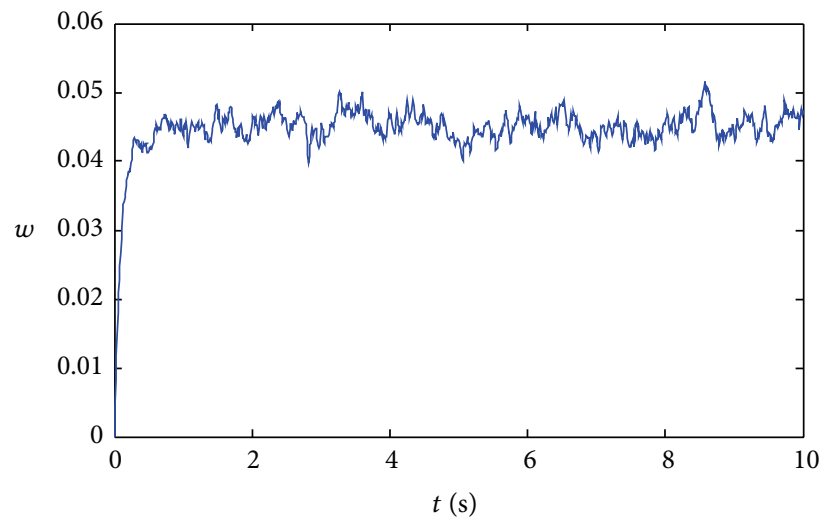

(d) $w-t$

FIgURE 1: Time domain of system (16).

with $t_{1}$ given by

$$
t_{1}=t_{0}+\frac{V^{1-\eta}\left(t_{0}\right)}{c(1-\eta)} .
$$

Then, the system could be stabilized in a finite-time $t_{1}$.

The design of sliding mode can generally be divided into two steps: Firstly, a sliding surface is constructed which is asymptotically stable and has good dynamic quality. Secondly, a sliding mode control law is designed such that the arrival condition is satisfied; thus the sliding mode is performed on the switching surface.

To control the unstable hydroturbine governing system, the control inputs are added to system (16); one has

$$
\begin{aligned}
\dot{x}= & 300 y+0.8 \text { rand }(1)+u_{1} \\
\dot{y}= & -\frac{2}{19} y+\frac{1}{19} z-\frac{1}{19}(1.08 \sin x+0.061 \sin 2 x) \\
& +0.1 \operatorname{rand}(1)+u_{2} \\
\dot{z}= & -2.5 z+6.6 w+0.5 \operatorname{rand}(1)+u_{3}, \\
\dot{w}= & -10 w+0.9 \text { rand }(1)+u_{4} .
\end{aligned}
$$

For the convenience of mathematical analysis, using $\left[x_{1}\right.$, $\left.x_{2}, x_{3}, x_{4}\right]$ instead of $[x, y, z, w]$, the unified form of system (20) could be presented as

$$
\dot{x}=f(x)+d(t)+u(t)
$$

where

$$
\begin{aligned}
& x=\left[x_{1}, x_{2}, x_{3}, x_{4}\right]^{T}, \\
& f(x) \\
& =\left[\begin{array}{c}
300 y \\
-\frac{2}{19} y+\frac{1}{19} z-\frac{1}{19}(1.08 \sin x+0.061 \sin 2 x) \\
-2.5 z+6.6 w \\
-10 w
\end{array}\right], \\
& d(t)=\left[\begin{array}{c}
0.8 \text { rand }(1) \\
0.1 \text { rand }(1) \\
0.5 \text { rand }(1) \\
0.9 \operatorname{rand}(1)
\end{array}\right] \\
& u(t)=\left[u_{1}, u_{2}, u_{3}, u_{4}\right]^{T} .
\end{aligned}
$$


The control target is to make the states $x=\left[x_{1}, x_{2}\right.$, $\left.x_{3}, x_{4}\right]^{T}$ track the setting value $x_{d}=\left[x_{d 1}, x_{d 2}, x_{d 3}, x_{d 4}\right]$. The tracking errors are defined as follows:

$$
e=x-x_{d}
$$

The error dynamics can be described as follows:

$$
\dot{e}=\dot{x}-\dot{x_{d}}=f(x)+d(t)+u-\dot{x_{d}} .
$$

Then the terminal sliding mode is defined as

$$
s=\alpha e+\int_{0}^{t} \beta|e|^{r} \operatorname{sat}(e) d \tau,
$$

where $\alpha, \beta, r$ are given positive real constants, with $0<r<$ 1. And

$$
\operatorname{sat}(e)= \begin{cases}\operatorname{sign}(e), & |e|>k \\ \frac{e}{k}, & |e| \leq k\end{cases}
$$

where $k$ is a positive constant; the value of $k$ is generally small. In general, the saturation function can effectively suppress the chattering phenomenon.

When the system state reaches the sliding surface, the following equality is satisfied:

$$
s=\dot{s}=0
$$

Based on (25) and (27), one has

$$
\dot{s}=\alpha \dot{e}+\beta|e|^{r} \text { sat }(e)=0 .
$$

Once an appropriate sliding surface is established, the next step of the method is to construct an input signal $u(t)$ which can make the state trajectories reach to the sliding surface $s(t)=0$ and stay on it forever. The sliding mode control law is presented as follows:

$$
\begin{aligned}
u(t)= & -f(x)-\left(k s+\left(\xi+L|s|^{u}\right) \operatorname{sign}(s)\right) \\
& -\left(\frac{\beta}{\alpha}\right)|e|^{r} \text { sat }(e)+\dot{x_{d}},
\end{aligned}
$$

where $k, L, u$ are given positive constants, with $0<u<$ 1. $\xi$ is the bounded value of random perturbation with $\xi=$ $[0.8,0.5,0.1,0.9]^{T}$.

Theorem 2. If the terminal sliding surface is selected in the form of (28) and the control law is designed as (29), then the state trajectories of the hydroturbine governing system (20) will converge to the sliding surface in a finite time $T=(1 / \alpha k(1-$ $u)) \ln \left(\left(k|s(0)|^{1-u}+L\right) / L\right)$.

Proof. Selecting the Lyapunov function $V(t)=|s|$ and taking its time derivative, one can obtain

$$
\dot{V}(t)=\operatorname{sign}(s) \dot{s} .
$$

Substituting (28) into (30), there is

$$
\begin{aligned}
\dot{V}= & \operatorname{sign}(s)\left(\alpha \dot{e}+\beta|e|^{r} \operatorname{sat}(e)\right) \\
= & \operatorname{sign}(s)\left(\alpha\left(f(x)+d(t)+u-\dot{x}_{d}\right)+\beta|e|^{r} \operatorname{sat}(e)\right) \\
\leq & \operatorname{sign}(s)\left(\alpha\left(f(x)+u-\dot{x}_{d}\right)+\beta|e|^{r} \operatorname{sat}(e)\right) \\
& \quad+|\operatorname{sign}(s) \cdot \alpha d(t)| \\
\leq & \operatorname{sign}(s)\left(\alpha\left(f(x)+u-\dot{x}_{d}\right)+\beta|e|^{r} \operatorname{sat}(e)\right)+\alpha \xi .
\end{aligned}
$$

Based on (26) and (29),

$$
\begin{aligned}
\dot{V} & \leq \operatorname{sign}(s)\left(\alpha\left(f(x)+u-\dot{x}_{d}\right)+\beta|e|^{r} \operatorname{sat}(e)\right)+\alpha \xi \\
& =\operatorname{sign}(s)(\alpha(f(x)-f(x) \\
& -\left(k s+\left(\xi+L|s|^{u}\right) \operatorname{sign}(s)\right)-\left(\frac{\beta}{\alpha}\right)|e|^{r} \operatorname{sat}(e) \\
& \left.\left.+\dot{x}_{d}-\dot{x_{d}}\right)+\beta|e|^{r} \operatorname{sat}(e)\right)+\alpha \xi=\operatorname{sign}(s) \\
& \cdot\left(\alpha\left(-\left(k s+\left(\xi+L|s|^{u}\right) \operatorname{sign}(s)\right)\right)\right)+\alpha \xi=-\alpha k|s| \\
& -\alpha \xi-\alpha L|s|^{u}+\alpha \xi=-\alpha k|s|-\alpha L|s|^{u} \leq 0 .
\end{aligned}
$$

According to Lyapunov stability theory and Lemma 1, the state trajectories of the unstable hydroturbine governing system (20) will converge to $s(t)=0$ in a finite time asymptotically. Then the reaching time $T$ can be got as follows.

Based on inequality (32), one has

$$
\frac{d V}{d t}=\frac{d|s|}{d t} \leq-\alpha k|s|-\alpha L|s|^{u} .
$$

It is obvious that

$$
d t \leq \frac{-d|s|}{\alpha\left(k|s|+L|s|^{u}\right)}=-\frac{1}{1-u} \times \frac{d|s|^{1-u}}{\alpha\left(k|s|^{1-u}+L\right)} .
$$
obtain

Taking integral for both sides of (34) from 0 to $t_{r}$, one can

$$
\int_{0}^{t_{r}} d t \leq \int_{s(0)}^{s\left(t_{r}\right)}-\frac{1}{1-u} \times \frac{d|s|^{1-u}}{\alpha\left(k|s|^{1-u}+L\right)}
$$

Then,

$$
t_{r} \leq-\left.\frac{1}{\alpha k(1-u)} \ln \left(\alpha k|s|^{1-u}+\alpha L\right)\right|_{s(0)} ^{s\left(t_{r}\right)} .
$$

Setting $s\left(t_{r}\right)=0$, one gets

$$
t_{r} \leq \frac{1}{\alpha k(1-u)} \ln \frac{\left(k|s(0)|^{1-u}+L\right)}{L} .
$$

So the states trajectories of system (20) will converge to the sliding surface $s(t)=0$ in a finite time $T=(1 / \alpha k(1-$ $u)) \ln \left(\left(k|s(0)|^{1-u}+L\right) / L\right)$. This completes the proof. 


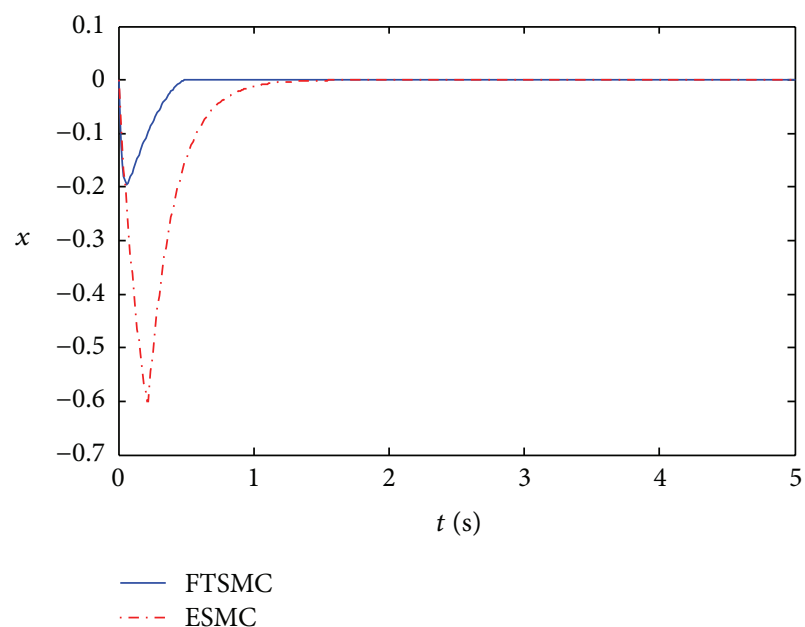

(a) $x-t$

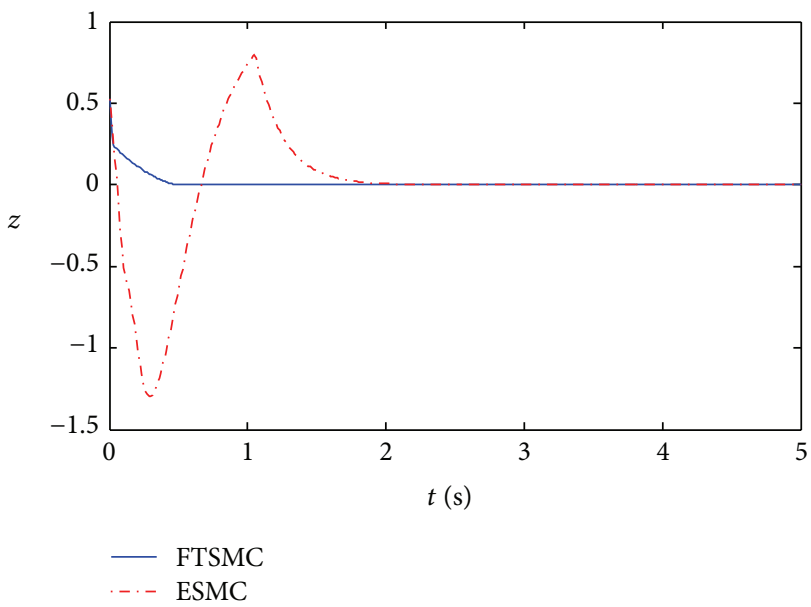

(c) $z-t$

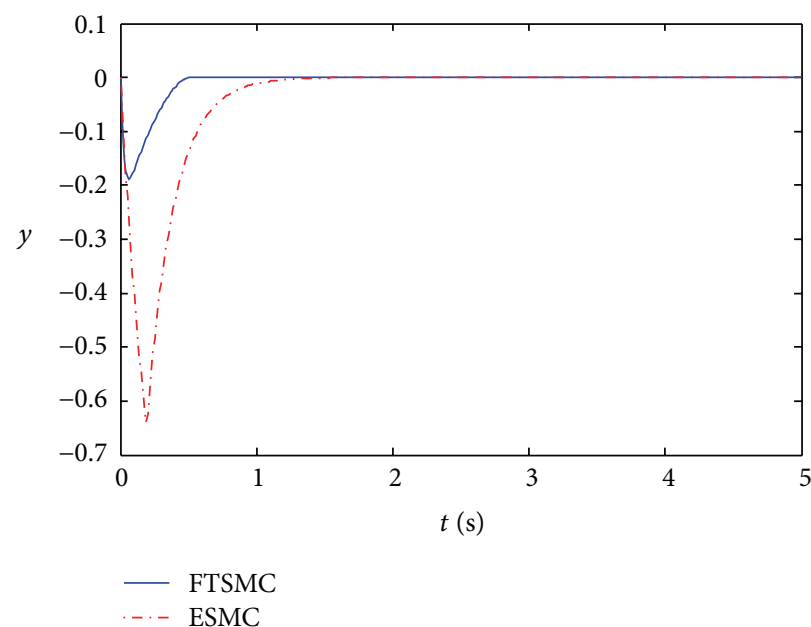

(b) $y-t$

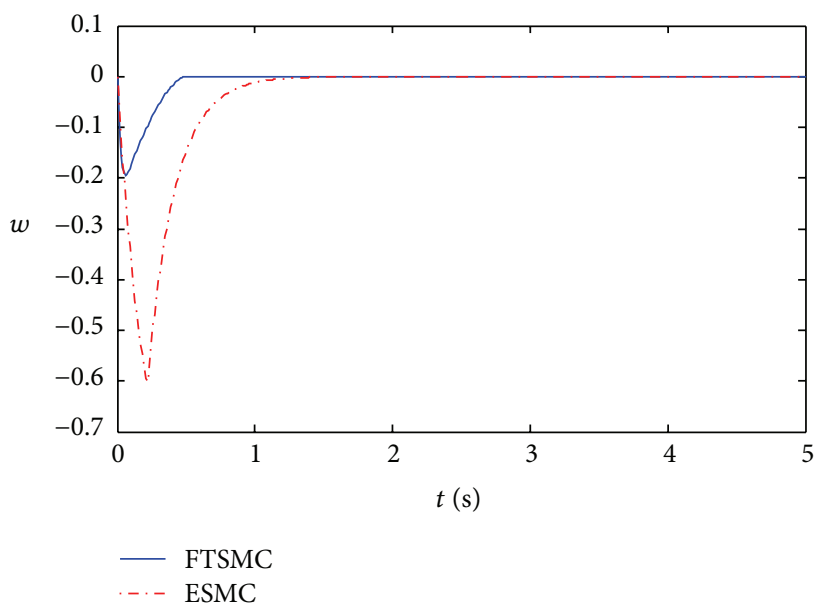

(d) $w-t$

FIGURE 2: Responses of controlled hydroturbine governing system (20).

\section{Numerical Simulations}

The parameters of the sliding surface (28) are selected as $\alpha=$ $4, \beta=6, r=0.4$. The parameters of the sliding mode control law (29) are selected as $k=1, L=8, u=0.4$.

According to (25), the sliding surfaces of the hydroturbine governing system are described as follows:

$$
s_{i}=4 e_{i}+\int_{0}^{t} 6\left|e_{i}\right|^{0.4} d \tau \quad(i=1,2,3,4) .
$$

Subsequently, the sliding mode control laws are given as follows:

$$
\begin{aligned}
u_{1}(t)= & -f_{1}(x)-\left(s_{1}+\left(0.8+8\left|s_{1}\right|^{0.4}\right) \operatorname{sign}\left(s_{1}\right)\right) \\
& -\left(\frac{6}{4}\right)\left|e_{1}\right|^{0.4} \operatorname{sat}\left(e_{1}\right)+\dot{x_{d 1}}, \\
u_{2}(t)= & -f_{2}(x)-\left(s_{2}+\left(0.1+8\left|s_{2}\right|^{0.4}\right) \operatorname{sign}\left(s_{2}\right)\right) \\
& -\left(\frac{6}{4}\right)\left|e_{2}\right|^{0.4} \operatorname{sat}\left(e_{2}\right)+\dot{x}_{d 2},
\end{aligned}
$$

$$
\begin{aligned}
u_{3}(t)= & -f_{3}(x)-\left(s_{3}+\left(0.5+8\left|s_{3}\right|^{0.4}\right) \operatorname{sign}\left(s_{3}\right)\right) \\
& -\left(\frac{6}{4}\right)\left|e_{3}\right|^{0.4} \operatorname{sat}\left(e_{3}\right)+x_{d 3}^{\cdot}, \\
u_{4}(t)= & -f_{4}(x)-\left(s_{4}+\left(0.9+8\left|s_{4}\right|^{0.4}\right) \operatorname{sign}\left(s_{4}\right)\right) \\
& -\left(\frac{6}{4}\right)\left|e_{4}\right|^{0.4} \operatorname{sat}\left(e_{4}\right)+\dot{x}_{d 4}^{\cdot} .
\end{aligned}
$$

Initial value of the hydroturbine governing system is selected as $x=[0,0, \pi / 6,0]$. In this study, the fixed point $x_{d}=[0,0,0,0]$ is set. In order to illustrate the superiority of the designed finite-time terminal sliding mode control (FTSMC) in this paper, the existing sliding mode control (ESMC) method in [30] is performed also. The state trajectories of the controlled hydroturbine governing system are shown in Figure 2.

It is clear that the proposed method can stabilize the hydroturbine governing system in a finite time. Compared with the technique presented in [30], the transition time is 
shorter and the overshoot is less which show the effectiveness and superiority of the designed control scheme. Compared with the conventional terminal sliding mode control algorithms, it is obvious that the new method promoted in this paper can resist external random disturbances, which will be of great significance and very suitable for the stability control of hydroturbine governing system.

\section{Conclusions}

In this paper, a finite-time control scheme was studied for the nonlinear vibration control of a Francis hydroturbine governing system. By using the modularization modeling method, combined with the two-order generator model, the mathematical model of a Francis hydroturbine governing system was established firstly. Then, based on the finitetime theory and the terminal sliding mode control method, a novel robust finite-time terminal sliding mode control scheme was proposed for the stability control of HGS. Finally, numerical simulations verified the robustness and superiority of the proposed method. In the future, this approach will be extended to other hydroturbine governing systems, such as hydropower systems with fractional order or time delay.

\section{Competing Interests}

The authors declare that there is no conflict of interests regarding the publication of this paper.

\section{Acknowledgments}

This work was supported by the scientific research foundation of the National Natural Science Foundation (51509210 and 51479173), the Science and Technology Project of Shaanxi Provincial Water Resources Department (Grant no. 2015slkj11), the 111 Project from the Ministry of Education of China (B12007), and Yangling Demonstration Zone Technology Project (2014NY-32).

\section{References}

[1] R. E. Grumbine and J. Xu, "Mekong hydropower development," Science, vol. 332, no. 6026, pp. 178-179, 2011.

[2] B. Lehner, G. Czisch, and S. Vassolo, "The impact of global change on the hydropower potential of Europe: a model-based analysis," Energy Policy, vol. 33, no. 7, pp. 839-855, 2005.

[3] D. Ling and Y. Tao, "An analysis of the Hopf bifurcation in a hydroturbine governing system with saturation," IEEE Transactions on Energy Conversion, vol. 21, no. 2, pp. 512-515, 2006.

[4] H. H. Chernet, K. Alfredsen, and G. H. Midttømme, "Safety of hydropower dams in a changing climate," Journal of Hydrologic Engineering, vol. 19, no. 3, pp. 569-582, 2014.

[5] C. L. Li, J. Z. Zhou, S. Ouyang, X. L. Ding, and L. Chen, "Improved decomposition-coordination and discrete differential dynamic programming for optimization of large-scale hydropower system," Energy Conversion and Management, vol. 84, pp. 363-373, 2014.
[6] X. D. Lai, Y. Zhu, G. L. Liao, X. Zhang, T. Wang, and W. B. Zhang, "Lateral vibration response analysis on shaft system of hydro turbine generator unit," Advances in Vibration Engineering, vol. 12, no. 6, pp. 511-524, 2013.

[7] Y. Xu, Z. H. Li, and X. D. Lai, "Dynamic model for hydro-turbine generator units based on a database method for guide bearings," Shock and Vibration, vol. 20, no. 3, pp. 411-421, 2013.

[8] X. Yu, J. Zhang, and L. Zhou, "Hydraulic transients in the long diversion-type hydropower station with a complex differential surge tank," The Scientific World Journal, vol. 2014, Article ID 241868, 11 pages, 2014.

[9] W.-Q. Sun and D.-M. Yan, "Identification of the nonlinear vibration characteristics in hydropower house using transfer entropy," Nonlinear Dynamics, vol. 75, no. 4, pp. 673-691, 2014.

[10] F.-J. Wang, W. Zhao, M. Yang, and J.-Y. Gao, "Analysis on unsteady fluid-structure interaction for a large scale hydraulic turbine II. Structure dynamic stress and fatigue reliability," Journal of Hydraulic Engineering, vol. 43, no. 1, pp. 15-21, 2012.

[11] Y. Zeng, L. X. Zhang, Y. K. Guo, J. Qian, and C. L. Zhang, “The generalized Hamiltonian model for the shafting transient analysis of the hydro turbine generating sets," Nonlinear Dynamics, vol. 76, no. 4, pp. 1921-1933, 2014.

[12] W. Tan, "Unified tuning of PID load frequency controller for power systems via IMC," IEEE Transactions on Power Systems, vol. 25, no. 1, pp. 341-350, 2010.

[13] A. Zargari, R. Hooshmand, and M. Ataei, "A new control system design for a small hydro-power plant based on particle swarm optimization-fuzzy sliding mode controller with Kalman estimator," Transactions of the Institute of Measurement and Control, vol. 34, no. 4, pp. 388-400, 2012.

[14] Y. K. Bhateshvar, H. D. Mathur, H. Siguerdidjane, and S. Bhanot, "Frequency stabilization for multi-area thermal-hydro power system using genetic algorithm-optimized fuzzy logic controller in deregulated environment," Electric Power Components and Systems, vol. 43, no. 2, pp. 146-156, 2015.

[15] Z. H. Xiao, Z. P. An, S. Q. Wang, and S. Q. Zeng, "Research on the NNARX model identification of hydroelectric unit based on improved L-M algorithm," Advanced Materials Research, vol. 871, pp. 304-309, 2014.

[16] C. S. Li, J. Z. Zhou, J. Xiao, and H. Xiao, "Hydraulic turbine governing system identification using T-S fuzzy model optimized by chaotic gravitational search algorithm," Engineering Applications of Artificial Intelligence, vol. 26, no. 9, pp. 20732082, 2013.

[17] Z. H. Chen, X. H. Yuan, H. Tian, and B. Ji, "Improved gravitational search algorithm for parameter identification of water turbine regulation system," Energy Conversion and Management, vol. 78, pp. 306-315, 2014.

[18] J. Song and S. P. He, “Observer-based finite-time passive control for a class of uncertain time-delayed Lipschitz nonlinear systems," Transactions of the Institute of Measurement and Control, vol. 36, no. 6, pp. 797-804, 2014.

[19] M. J. Cai and Z. R. Xiang, "Adaptive fuzzy finite-time control for a class of switched nonlinear systems with unknown control coefficients," Neurocomputing, vol. 162, pp. 105-115, 2015.

[20] M. P. Aghababa, "Robust stabilization and synchronization of a class of fractional-order chaotic systems via a novel fractional sliding mode controller," Communications in Nonlinear Science and Numerical Simulation, vol. 17, no. 6, pp. 2670-2681, 2012.

[21] A. Marcos-Pastor, E. Vidal-Idiarte, A. Cid-Pastor, and L. Martínez-Salamero, "Loss-free resistor-based power factor correction using a semi-bridgeless boost rectifier in sliding-mode 
control," IEEE Transactions on Power Electronics, vol. 30, no. 10, pp. 5842-5853, 2015.

[22] D. Y. Chen, R. F. Zhang, J. C. Sprott, H. T. Chen, and X. Y. $\mathrm{Ma}$, "Synchronization between integer-order chaotic systems and a class of fractional-order chaotic systems via sliding mode control," Chaos, vol. 22, no. 2, Article ID 023130, 2012.

[23] B. J. Zhang and H. G. Guo, "Universal function projective lag synchronization of chaotic systems with uncertainty by using active sliding mode and fuzzy sliding mode control," Nonlinear Dynamics, vol. 81, no. 1-2, pp. 867-879, 2015.

[24] S. H. Yu, X. H. Yu, B. Shirinzadeh, and Z. H. Man, "Continuous finite-time control for robotic manipulators with terminal sliding mode," Automatica, vol. 41, no. 11, pp. 1957-1964, 2005.

[25] M. Ou, H. Du, and S. Li, "Finite-time formation control of multiple nonholonomic mobile robots," International Journal of Robust and Nonlinear Control, vol. 24, no. 1, pp. 140-165, 2014.

[26] S. Khoo, L. H. Xie, S. K. Zhao, and Z. H. Man, "Multi-surface sliding control for fast finite-time leader-follower consensus with high order SISO uncertain nonlinear agents," International Journal of Robust and Nonlinear Control, vol. 24, no. 16, pp. 2388-2404, 2014.

[27] L. Li, Q. L. Zhang, J. Li, and G. L. Wang, "Robust finite-time $H_{\infty}$ control for uncertain singular stochastic Markovian jump systems via proportional differential control law," IET Control Theory \& Applications, vol. 8, no. 16, pp. 1625-1638, 2014.

[28] P. F. Curran and L. O. Chua, "Absolute stability theory and the synchronization problem," International Journal of Bifurcation and Chaos in Applied Sciences and Engineering, vol. 7, no. 6, pp. 1375-1382, 1997.

[29] J. L. Yin, S. Khoo, Z. H. Man, and X. H. Yu, "Finite-time stability and instability of stochastic nonlinear systems," Automatica, vol. 47, no. 12, pp. 2671-2677, 2011.

[30] D.-Y. Chen, W.-L. Zhao, X.-Y. Ma, and R.-F. Zhang, "Nochattering sliding mode control chaos in Hindmarsh-Rose neurons with uncertain parameters," Computers and Mathematics with Applications, vol. 61, no. 10, pp. 3161-3171, 2011. 


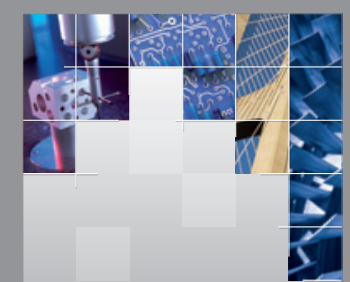

\section{Enfincering}
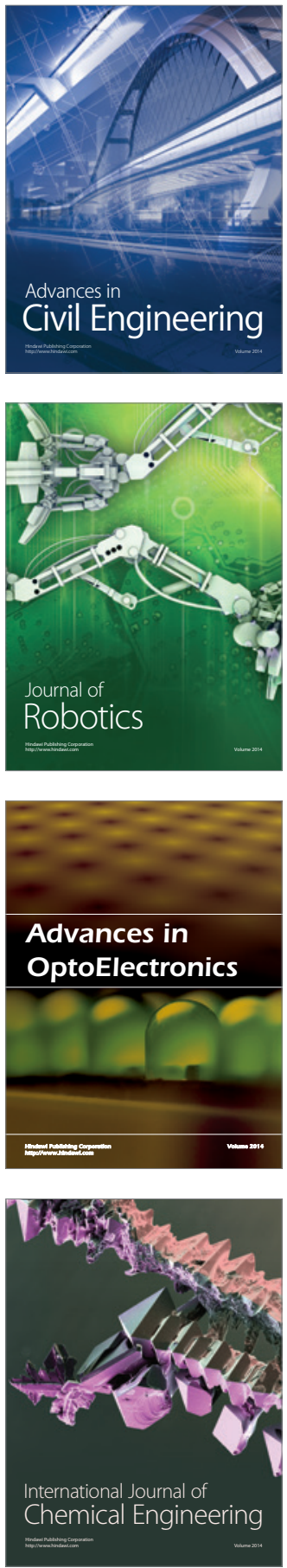

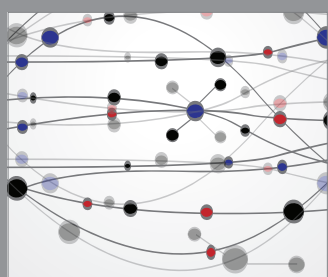

The Scientific World Journal

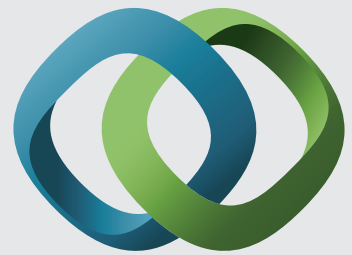

\section{Hindawi}

Submit your manuscripts at

http://www.hindawi.com
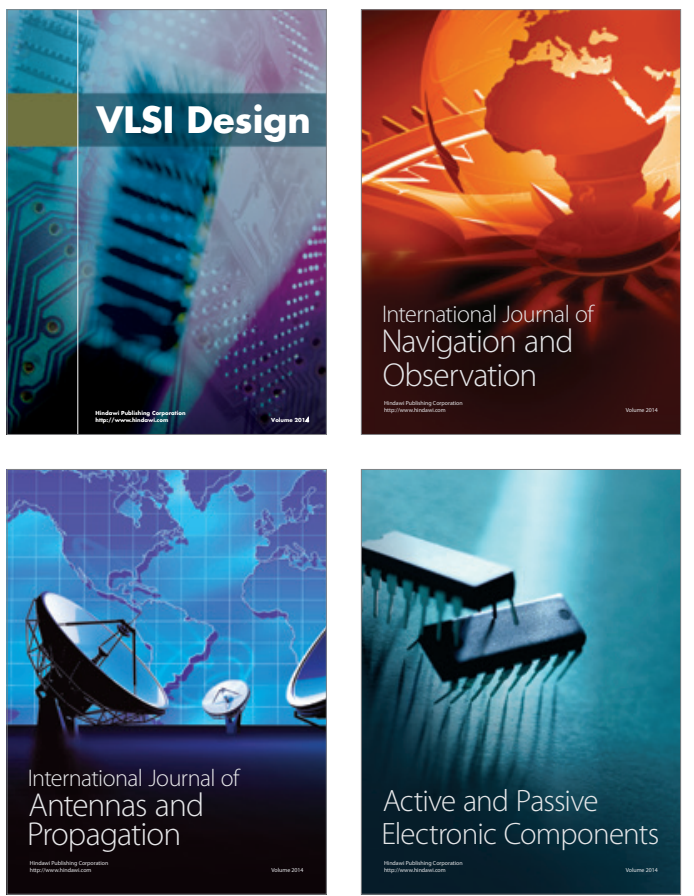
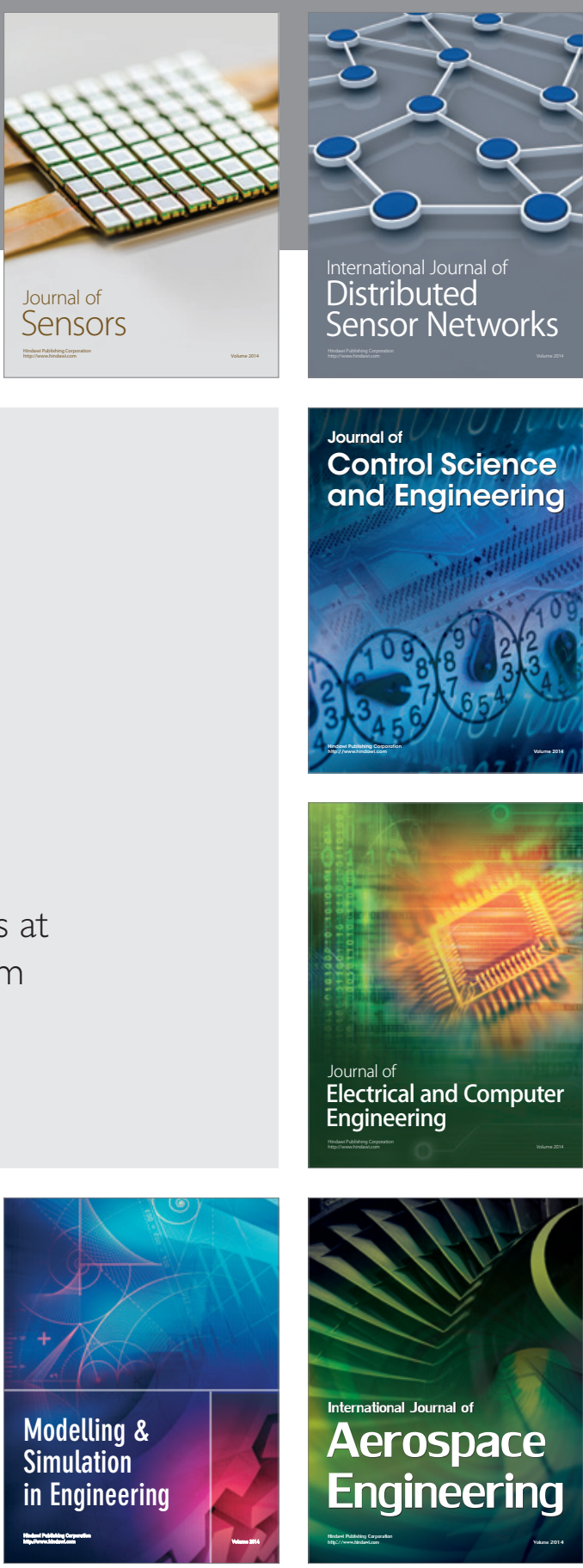

International Journal of

Distributed

Sensor Networks

Journal of

Control Science

and Engineering
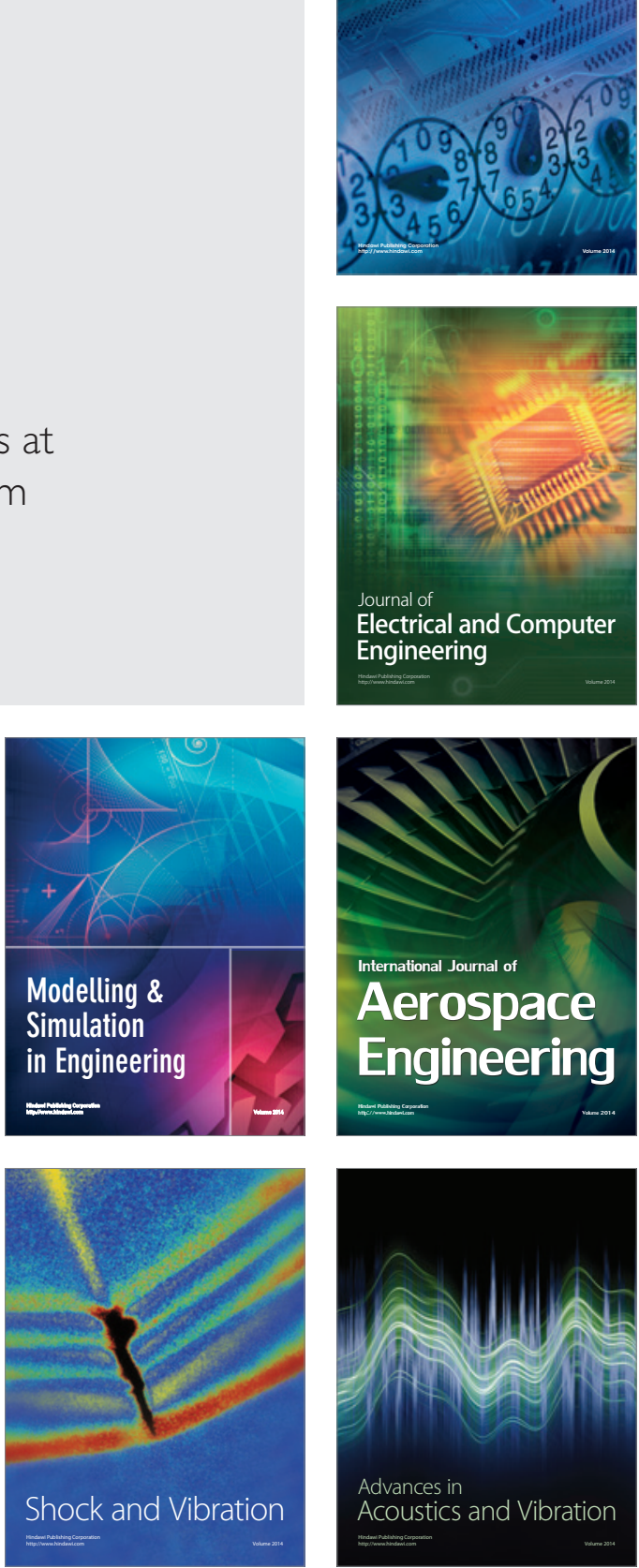